\title{
Iron ore deposits model using geoelectrical resistivity method with dipole-dipole array
}

\author{
Adree Octova ${ }^{1, *}$, and Dedi Yulhendra ${ }^{1}$ \\ ${ }^{1}$ Mining Engineering Department Faculty of Engineering, State University of Padang, 25131 Padang, Indonesia
}

\begin{abstract}
Mining industry is an industry with very high risk (losses). In order that mining activities can be run well, then the potential of the Earth's resources must be known for sure. one of the Earth's resources of high economic value is the iron ore. Iron ore is rarely found in a free state in nature, it is usually associated with other minerals and exposed randomly. With these properties, iron ore needs to be modeled before doing mining activities in order to avoid large losses. Iron ore deposits can be modeled with geoelectrical resistivity method. Dipole-dipole array will produce good imaging both vertically and laterally. From the measurement results of geoelectrical resistivity with dipole-dipole array will be obtained the value of measuring the current and potential difference. This value will generate into $2 \mathrm{D}$ and $3 \mathrm{D}$ model of the cross section of the iron ore deposits. One of the areas in West Sumatra has the potential for iron ore. Five lines were applied in this area. The result of cross section got the iron minerals associated with quartzite at 30 meters depth below the surface.
\end{abstract}

\section{Introduction}

Iron is one of the natural resources that most abundant in nature and most use in life. Iron found in nature in form of compounds, such as hematite, magnetite, pyrite and siderite. From iron ore minerals, magnetite is a mineral with the highest Fe but there is a small amount. While hematite is the main ore mineral needed in the iron industry. One of the uses of iron ore is as steelmaking material. Basically, there are a lot of iron ore mineral as well as contact metasomatik secondary sludge buried and exposed randomly.

In practice, the exploration activities carried out by utilizing the properties of physics and chemistry of rocks, soil, elements and minerals, such as: magnetism, density, electricity, radioactivity, and mobility elements. There are several methods that can be used to describe these properties, one of them is indirect exploration method. These method is applied at the early stages of exploration, which time and cost are quite limited.

Geoelectrical method is one of indirect exploration method that is often used in mining exploration. In addition to the cost of exploration costs, this method is also pretty well describes the rock layers below the surface.

Geoelectrical resistivity has several electrode arrangement in providing a picture of the earth's subsurface, one of them is dipole-dipole array. The arrangement of dipole-dipole electrode array is different from the Wenner and Schlumberger array. For the dipole-dipole array, current and potential electrodes are arranged separately, longer line will be further away. While the Wenner and Schlumberger array will provide potential electrode arrangement in which current electrode arrangement in conjunction with the long line.

The differences of array will give the different appearance of subsurface models. Based on [3][5], Schlumberger array will provide a better picture for the vertical model with a deeper current distribution. Wenner array will provide a better picture laterally with more shallow current distribution than Schlumberger array [6][7]. While the dipole-dipole array provides better picture vertically and laterally with deeper current distribution than two electrode array mentioned above[8][11][13].

See the random distribution of iron ore, it will be easier to interpret the iron ore by modeling with dipoledipole array. The result model of the dipole-dipole array can be modeled in 2D and 3D display. The cost of this array is not expensive when compared with Wenner and Schlumberger. This configuration can also be used for mapping, ie measurement focuses laterally results.

The purpose of this study was:

- Provide an overview of the subsurface using geoelectrical resistivity method with dipole-dipole array.

- Provide information of iron in the study area in the form of 2D and 3D models of geoelectrical resistivity method with dipole-dipole array.

\section{Electrical properties of rocks and minerals}

The electrical properties of rocks is characteristic of rocks when electric current flows into it. Electric current

Corresponding author: adree.octova@gmail.com 
can be derived from nature caused by the presence of the atoms making up the earth's crust that interact with each other due to the charge imbalance, or electric current accidentally put into it. Some of the electrical properties of rocks that are useful in the geoelectrical exploration particularly in resistivity method is the natural electrical potential, electrical conductivity, and dielectric constant.

Based on the value of resistivity, rocks and minerals can be classified into: a good conductor with resistivity value of $10^{-6} \Omega \mathrm{m}$ to $1 \Omega \mathrm{m}$, bad conductor with resistivity value of $1 \Omega \mathrm{m}$ to $10^{7} \Omega \mathrm{m}$, and isolator with resistivity value of greater than $10^{7} \Omega \mathrm{m}$ [1]. It means conductive material will has smaller the resistivity value, and isolator material has greater the resistivity value.

Earth material has no fixed resistivity value, in other word has a specific range. Resistivity material depends on the state of the geology and rocks structure at each location [4]. The range of resistivity value of some materials shown in Table 1 [9].

Table 1. Resistivity of rocks and minerals

\begin{tabular}{|l|l|}
\hline Rock/mineral & Resistivity $(\mathbf{\Omega m})$ \\
\hline Topsoil & $50-100$ \\
\hline Loose sand & $500-5000$ \\
\hline Gravel & $100-600$ \\
\hline Clay & $1-100$ \\
\hline Weathered bedrock & $100-1000$ \\
\hline Sandstone & $200-8000$ \\
\hline Limestone & $500-10000$ \\
\hline Greenstone & $500-200000$ \\
\hline Gabbro & $100-500000$ \\
\hline Granite & $200-100000$ \\
\hline Basalt & $200-100000$ \\
\hline Kuarsite & $100-2500000$ \\
\hline Graphitic schist & $10-500$ \\
\hline Slates & $500-500000$ \\
\hline Pyrite (ores) & $0.01-100$ \\
\hline Phyrotite & $0.001-0.01$ \\
\hline Chalcopyrite & $0.005-0.1$ \\
\hline Galena & $0.001-100$ \\
\hline Sphalerite & $1000-1000000$ \\
\hline Magnetite & $0.01-1000$ \\
\hline Cassiterite & $0.001-10000$ \\
\hline Hematite & $0.01-1000000$ \\
\hline
\end{tabular}

\section{Geoelectrical resistivity}

Geoelectrical method is one of the geophysics methods that studies the current distribution properties in subsurface. The response is based on the measurement of potential field and current on the surface that occur either naturally or due to the injection of the current into the earth. Some of geoelectrical method are: self potential method (SP), Telluric currents, magnetotelluric, electromagnetic, induced polarization (IP) and resistivity method.

Resistivity method is one of geoelectrical method that used to study current distribution based on the differences of rock resistivity. The basic principle of this method is injected the current into the earth using two current electrodes, then measure the potential difference through two other electrodes on the surface of the earth. The current will flow through the rock layers below the surface, and generate data potential difference whose value depends on the resistivity of rock [13]. Based on the value of resistivity, the subsurface structure and constituent materials of the earth can be known.

The resistivity measurement is generally related to the size of the saturation and pore spaces of water. Water has a low resistivity, so that the current will follow the flow of the smallest resistivity [2]. Saturation, salinity of groundwater, and porosity rocks increasing will reduce the resistivity value. Increasing soil or rock compaction unit will chase away water and effectively increase the value of resistivity. Air has a high resistivity value, resulting in the exact opposite response to water when filling pores. As the result, the presence of water will reduce the resistivity value, whereas the presence of air in pores increase the resistivity value below the earth's surface.

Generally, the simple approach of earth current properties is thinking the earth as a homogeneous isotropic medium. Assuming the current field from a source point in the earth is spherical symmetries [13]. Fig.1. shows the current distribution on the earth as a homogeneous medium.

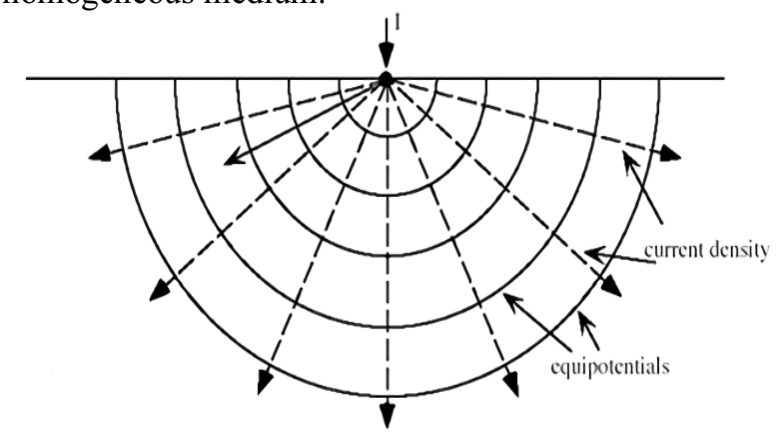

Fig. 1. Current distribution on earth as homogeneous medium [13]

The equation to calculate the resistivity of rock is:

$$
\rho=\frac{V}{l} 2 \pi r
$$

$\rho$ is resistivity material $(\Omega \mathrm{m}), r$ is radius $(\mathrm{m}), V$ is potential difference $(\mathrm{v}), I$ is current $(\mathrm{A})$.

Equation (1) can be simplified to

$$
\rho=k \frac{\Delta V}{I}
$$

$K$ is geometric factor. The $K$ value will depend on electrode array.

\section{Apparent resistivity}

Basic assumption of geoelectrical resistivity method is the earth with homogeneous isotropic medium that provides the same resistance values for the same electrode array [12]. But in fact, the Earth is composed of layers with different resistivity value. The measured potential difference is the influence of these layers [1]. 
The measured resistivity is the value of pseudo (apparent) on various rocks [10], this resistivity is called the apparent resistivity. Apparent resistivity is the resistivity of a fictitious homogeneous medium equivalent with layered medium that reviewed for one layer.

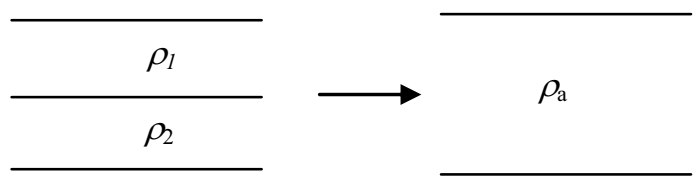

Fig. 2. Apparent resistivity concept [1]

Fig.2. shows the concept of apparent resistivity with layered medium assumption that consists of two different resistivity layers $\left(\rho_{1}\right.$ and $\left.\rho_{2}\right)$. This medium is considered as one homogeneous medium layer which has one resistivity value that is measured apparent resistivity $\rho_{\mathrm{a}}$. Based on this explanation, (2) can be written as:

$$
\rho_{a}=K \frac{\Delta V}{I}
$$

with $\rho \mathrm{a}$ is apparent resistivity. The data analysis of apparent resistivity will produce actual resistivity of Earth.

\section{Dipole-dipole array}

The data of measured resistivity is plotted at corresponding points to the value of $n(n=1,2,3,4,5,6)$ with the apparent depth level, so that it can be made pseudodepth section contours of resistivity variations to lateral direction toward the direction of the apparent depth.

The results of measurement using more spaces between current and potential electrode will give deeper information on subsurface structure. Thus, the dipoledipole configuration can be effectively in mapping, both laterally and vertically (Fig.3).

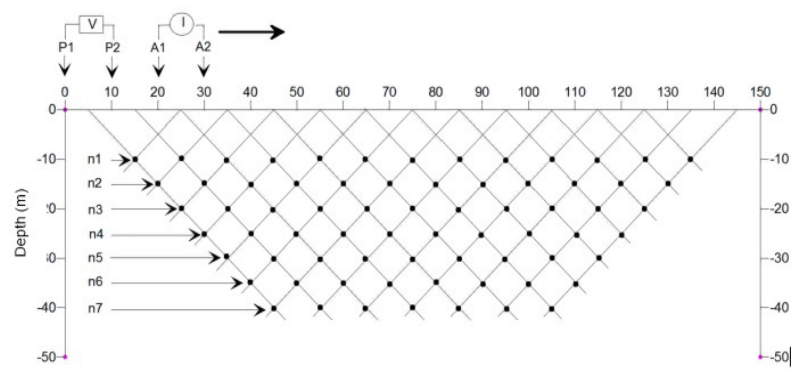

Fig. 3. Electrode array of dipole-dipole

In dipole-dipole array, both current and potential electrode sare separated by distance "a". While the current and the electrode potential inside are separated section as far as "na", where $\mathrm{n}$ is an integer. Variations of " $n$ " is used to get a certain depth, greater " $n$ " will obtain bigger depth. The level of range sensitivity of the dipole-dipole array is affected by the value of "a" and "n" variation [5].

\section{Design of measurement}

Regionally, the research area is situated on the path of magmatic. As an active path magmatic, then along this zone has potential mineralization (Fig.4). The liquid magma rises to the top interacting with groundwater forming rich mineral hydrothermal fluids, rise up through the fault as a weak zone and settles on fractures or porous of rock.

Lithologies contained in the investigation area from old to young, as follows, namely:

- Quartzite and quartz sandstones, shales, conglomerates, regionally included in the lithologies of the Lower Formation Kuantan Member in Perm aged.

- Slate, black shale, regionally included in the Triassic Formation in Tuhur aged.

- Granite, structure ranges from leucogranit to quartz monzonite, Triassic aged, gray-green, massive structures, mineral composition of quartz, plagioclase, hornblende.

Based on observations in the research area obtained a few chunks of rock containing iron ore found as a result of transportation that expected not far from its original location seen from the angle of that angled boulder. Mineralization of iron ore deposits are found in the form of boulder of quartzite and granite gravel containing mineral magnetite spots that found along the river

Measurements were taken at the block X on one of iron ore mining in West Sumatra. Design of measurement is performed with 5 lines with 50 meters distance between the lines and 300 meters long line. Measurements were made from South to North direction (Fig.5).

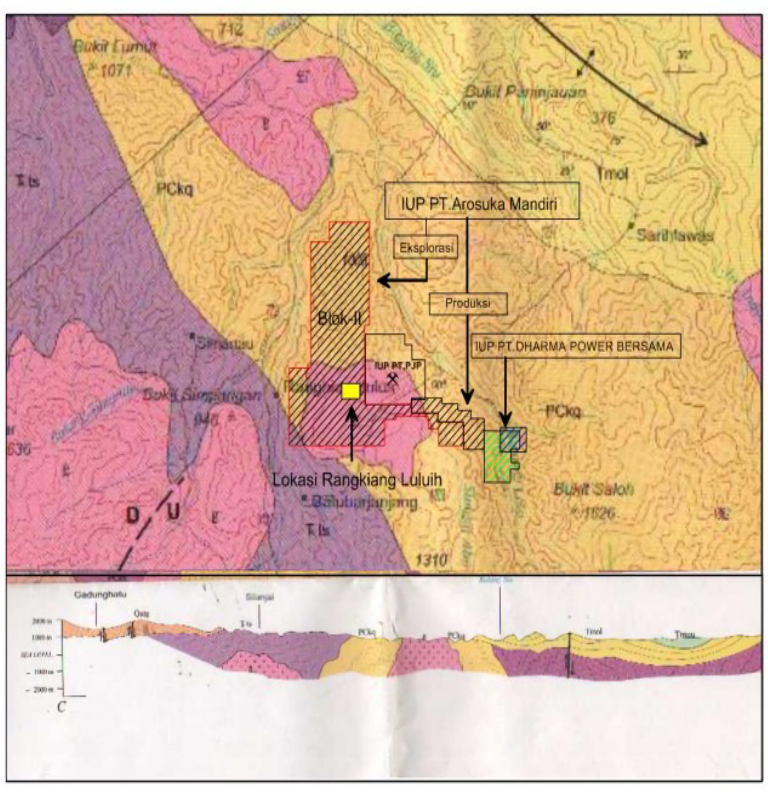

Fig. 4. Regional geological of research area 


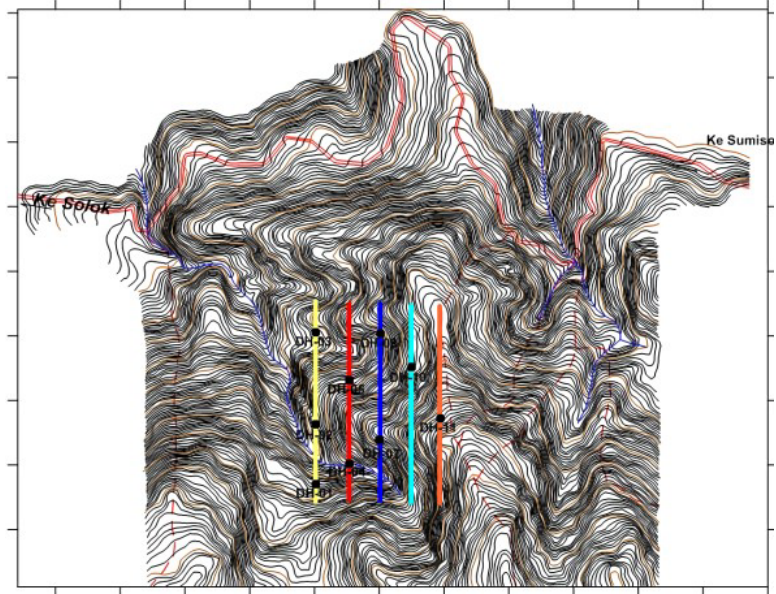

Fig. 5. Design of measurements

\section{Results and discussion}

Data obtained from geoelectrical measurements are potential difference, electrical current, and geometric factor. The data is then processed to find apparent resistivity using (3) and will be obtained 2D crosssection using geolectical resistivity software. The measurement results are illustrated in geoelectrical crosssection line 1 to line 5. Geoelectrical measurements was using 5 meters, 10 meters and 20 meters electrodes space along 300 meters line. With the following results:

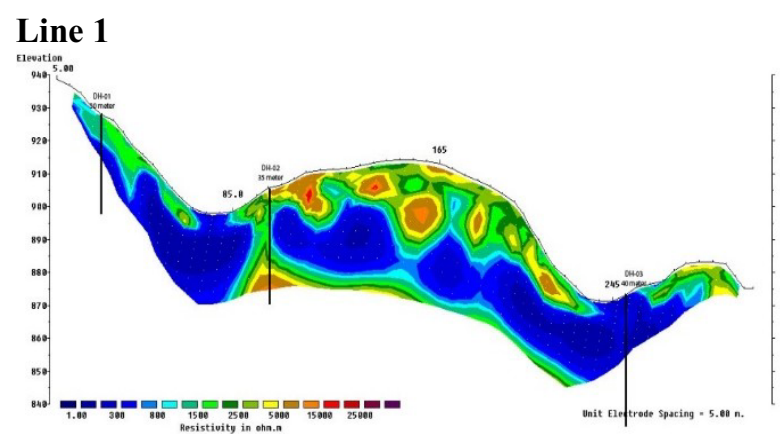

Fig. 6. Cross-section line 1

Resistivity value in line 1 has range $18.56 \Omega \mathrm{m}$ to $18855.5 \Omega \mathrm{m}$ (Fig.6). Based on resistivity value, line 1 has three layers, namely:

- The first layer is a soil layer in the form of clay. Yellow to orange color supposedly is a boulder of quartzite rocks were transported from elsewhere.

- The second layer is dominated by clay, a dark blue color is suspected of clay containing water. The blue color that is closely to the third layer presumably of iron, because the drilling results has weathering of quartzite containing little iron at a depth of 18 meters to 30 meters. The weathering is thought same with line 2 because iron also found in this the second layer. While the blue color in the centre of cross section is a layer of clay and schist. This is reinforced by the discovery of a layer of clay and schist in the drilling point. In the end of line 1 is clay that contains lots of pyrite. While the light blue color on the boundary layer is the boundary between clay, schist and quartzite rock intrusions.
- The third layer is an intrusion of quartzite rock, the drilling results obtained quartzite rock layers that contain iron minerals at a depth of 30 meters to 35 meters.

\section{Line 2}

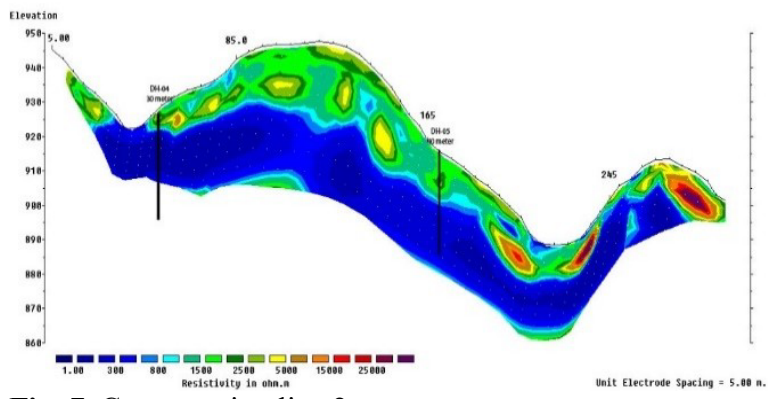

Fig. 7. Cross-section line 2

Resistivity value in line 2 has range $1.19 \Omega \mathrm{m}$ to 75429.4 $\Omega \mathrm{m}$ (Fig.7). Line 2 has three layers:

- The first layer is a layer of soil in the form of clay. Green color to yellow is boulders of quartzite rock. Yellow to purple color at the end of line is granite lifted upwards due to fracture of the rock nearby.

- The second layer has the similar rock properties with the line 1.

- The third layer is an intrusion of quartzite rock, the drilling results obtained quartzite rocks that contain iron minerals in 15 meters depth. Quartzite layer containing iron were also found in line 1 .

\section{Line 3}

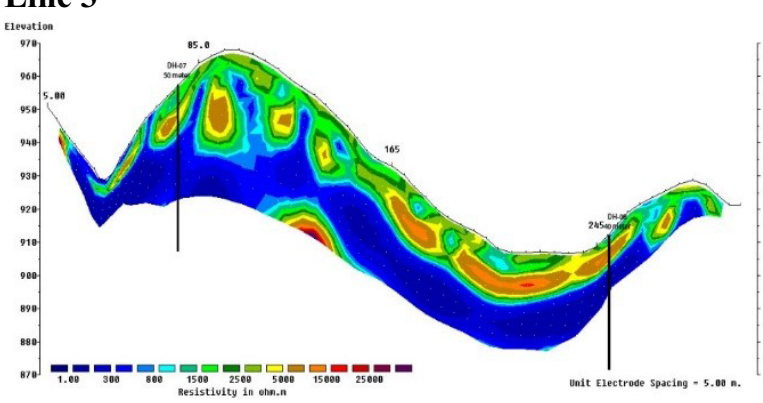

Fig. 8. Cross-section line 3

Resistivity value in line 3 has range $2.28 \Omega \mathrm{m}$ to 58567.3 $\Omega \mathrm{m}$ (Fig.8). There are three layers that identified in this line.

- The first layer is a layer of clay that there are many weathering of quartzite. Light blue color in this layer is sand as the result of quartzite weathered rocks that contain iron and has low resistivity value.

- The second layer below the point of 0 to 100 meters from the geoelectrical measurements is a layer of clay that contains lots of water as it is above the layer there is a stream. The iron indication caused of the possibility of iron in line 1 and 2 are still a part of line 3 in the second layer. While at 100 to 200 meters is a layer of clay and schist, it is obtained from the drilling results. Layers of schist and clay in line 3 is believed to be the unity of connecting layer from line 1 to line 3 . At the point of 200 to 300 meters is a mixed layer of clay and pyrite. 
- The third layer is an intrusion of quartzite rock. The drilling results obtained quartzite rock layers that contain iron minerals.

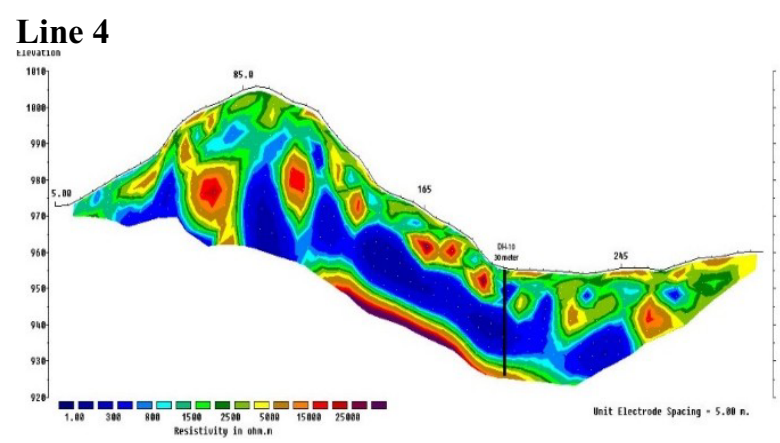

Fig. 9. Cross-section line 4

Resistivity value in line 4 has range $24.66 \Omega \mathrm{m}$ to 89475.3 $\Omega \mathrm{m}$ (Fig.9). The contain layer in this cross section:

- The first layer of this line almost similar with other layers in previous lines. The layer contain soil in form of clay. There is also quartzite rocks containing iron with small resistivity value.

- The second layer below point 0 to 100 meters from geoelectrical measurements is weathering of quartzite and containing iron. At the point of 100 to 300 meters has a clay containing pyrite.

- The third layer is quartzite intrusion. Because of resistivity value in this layer is almost equal with quartzite resistivity value in previous lines, so there is connection of this layer with previous layer. However, the high resistivity value of this layer make possible the iron contained on quartzite intrusion measly or no at all.

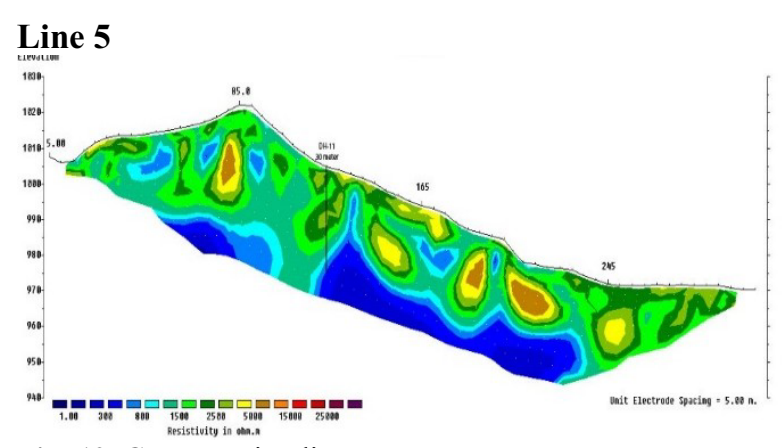

Fig. 10. Cross-section line 5

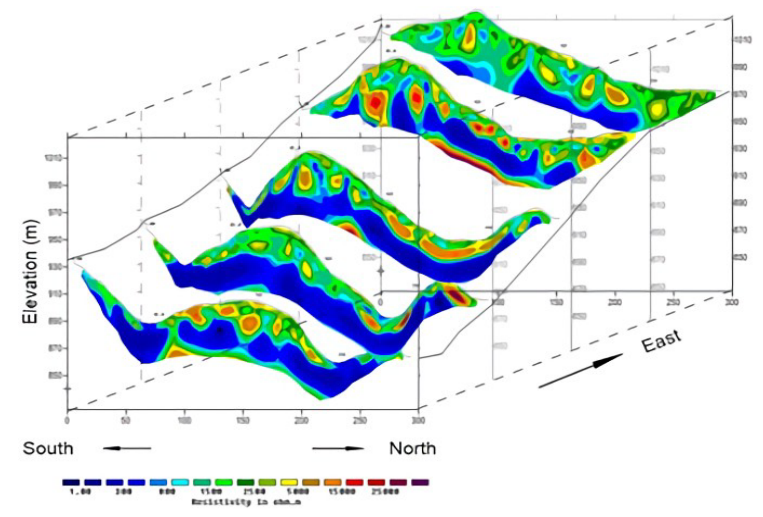

Fig. 11. Combination of 5 cross-sections
Resistivity value in line 5 has range $56.3 \Omega \mathrm{m}$ to 10181.3 $\Omega \mathrm{m}$ (Fig.10). There are only two layers in this line.

- The first layer is clay with many boulders of quartzite. The presence of blue color on this line is probably the clay fill the gaps between the quartzite boulders.

- The second layer of this line is clay with 20 meters thickness.

The results of geological mapping and outcrop on the field, the presence of iron in the research area are in quartzite and granite rocks (Fig.11). However, not all of quartzite and granite rock contains iron minerals due to discontinuous the nature of the iron mineralization. Thus, in interpretation of geoelectrical result, the resistivity value is thought to be the body of quartzite and granite rocks.

Based on the combined cross-sectional imaging and the results of previous 2D cross-sectional images, can be concluded:

a. Overburden in every line generally chunks clay of quartzite.

b. The second layer at points 200 to 300 meters of line 1 to 5 allegedly is a layer of clay that contains pyrite. This is certainly due to the continuity of the blue color in the area.

c. The second layer at the point of 0 to 200 meters of line 1 to 4 are suspected of quartzite layer containing iron and estimated blue color formed is a continuity of the iron.

d. The third layer is an intrusive rocks containing iron quartzite and this layer connects from the line 1 to 4 .

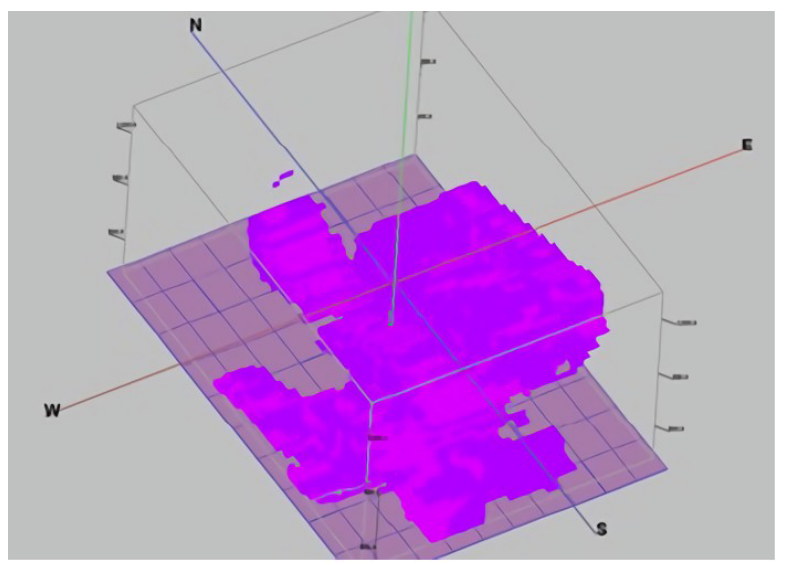

Fig. 12. 3D Resistivity Modeling

From the results of the 3D model (Fig.12), the iron is seperated in 30 to 40 meters below the surface. The concentration of the iron is more legible on the midpoint of the geoelectrical measurement, it caused midpoint has deeper current penetration.

\section{Conclusions}

Geoelectrical resistivity method with dipole-dipole array can provide a representative picture of the iron ore 
in the subsurface. It is seen from the cross section produced by the iron minerals associated with quartzite at 30 meters depth below the surface.

We thank to PT. Arosuka Mandiri West Sumatera for the permission in using the data.

\section{References}

1. Akmam. Elastisitas Zat Padat dan Batuan Serta Aspek Geofisiknya dan Metoda Geolistrik Tahanan Jenis. Jurusan Fisika. Fakultas Matematika dan Ilmu Pengetahuan Alam. Universitas Negeri Padang. (2002).

2. Cardimona, Steve. Electrical Resistivity Techniques for Subsurface Investigation. Department of Geology and Geophysics, University of MissouriRolla, Rolla, MO (2000).

3. Dahlin,T. and M.H. Loke. Resolution of 2D Wenner Resistivity Imaging as Assessed by Numerical Modelling, J. of App. Geophy. (1998).

4. Keller, George V. Electrical Properties of Rocks and Minerals, Cambridge University Press. (1990)

5. Loke, M.H. Electrical Imaging Surveys for Environmental and Engineering Studies, A Practical Guide to 2-D and 3-D Surveys. 5, Cangkat Minden Lorong 6, Minden Heights, 11700 Penang, Malaysia. (1999).
6. Loke, M.H. Electrical Imaging Surveys For Environmental And Engineering Studies, Penang, Malaysia. (2000).

7. Loke, M.H. 2D And 3D Electrical Imaging Surveys. Penang, Malaysia. (2002).

8. Loke, M.H. Rapid 2D Resistivity \& Ip Inversion Using The Least-Square Method, Penang, Malaysia. (2004).

9. Milsom, John. Field Geophysics. England. Willey. (2003)

10. Ocvianti, Marini A, I.Suyanto, E.Hartantyo. Pengolahan Data Resistivitas Mapping Menggunakan Program Probabilitas Tomografi. Prosiding Himpunan Ahli Geofisika, Pertemuan Ilmiah Tahunan ke-25. Bandung. (2000).

11. Reynolds, J.M. An Introduction To Applied And Environmental Geophysic, John Welly \& Sons. New York. (1997).

12. Sunaryo, A.Rachmansyah, D.Sisinggih. Penentuan Lapisan Aquifer dengan Metode Geolistrik Resistivitas di Desa Tempuran, Jatilangkung dan Awang-awang, Kec. Pungging, Kab. Mojokerto. Proceedings of Joint Convention Jakarta 2003. The 32nd IAGI and The 28th HAGI Annual Convention and Exhibition. (2003).

13. Telford, W.M, L.P.Geldart, R.E.Sheriff. Applied Geophysics Second Edition. Cambridge University Press. (1990). 